Research paper

\title{
Correlation between serum and salivary phenytoin drug metabolite levels to phenytoin influenced gingival overgrowth in adult male subjects. A prospective cohort study
}

\author{
Srirangarajan Sridharan*, Priyanka S \\ Department of Periodontics, Bangalore Institute of Dental Sciences and Post Graduate Research Centre, 5/3, Hosur Road, Bangalore, 560089 Karnataka, India
}

\section{A R T I C L E I N F O}

\section{Article history:}

Received 15 September 2016

Accepted 29 June 2017

Available online 18 July 2017

\begin{abstract}
A B S T R A C T
Background: To correlate serum and salivary phenytoin drug metabolite levels in males to phenytoin influenced gingival overgrowth (PIGO).

Methods: Thirty male patients who are to start with oral phenytoin therapy were recruited. Plaque index (PI), Gingival index (GI), and Oral hygiene index $(\mathrm{OHI})$ were recorded. Basic periodontal therapy was performed. Patients were followed up at 3, 6, 9 and 12 months intervals. Based on the gingival status they were divided in to two groups; Group1 (responders) and Group 2 (non responders). Serum and Salivary samples were analyzed for the drug metabolite levels spectophotometrically.

Results: The mean values of phenytoin drug metabolite levels in serum of group 1 and group 2 subjects were $14.5 \pm 2.6 \mu \mathrm{g} / \mathrm{ml}$ and $14.2 \pm 1.7 \mu \mathrm{g} / \mathrm{ml}$ respectively, with $\mathrm{p}$ value of 0.66 . The corresponding mean values of phenytoin drug metabolite levels saliva were $1.42 \pm 0.34 \mu \mathrm{g} / \mathrm{ml}$ and $1.38 \pm 0.37 \mu \mathrm{g} / \mathrm{ml}$ with $\mathrm{p}$ value of 0.75 . Correlation of phenytoin drug metabolite to PI, GI, and $\mathrm{OHI}$ in both the groups did not show any statistical significance. ( $\mathrm{R}$ values ranging from -0.229 to 0.434 ). Correlation between the serum and salivary drug metabolites in both the responder and non responder group also did not show any statistically significant relationship.

Conclusion: No correlation between the drug concentration in either the serum or saliva can be correlated to PIGO. Whole Saliva could be a useful tool in therapeutic drug monitoring of phenytoin.

Clinical relevance: Scientific rationale: To assess and compare the drug metabolite levels in serum and saliva of a neurologic condition where therapeutic drug concentration is of key importance to minimize the side effects. Principle finding: Saliva could be as useful as serum in deciding the drug concentration of phenytoin. And PIGO is not related drug concentrations. Practical implication: Monitoring the drug dosage is of paramount importance for the success of antiepileptic therapy as well as control of its side effects. This longitudinal study confirms that saliva could be an effective alternative to serum for monitoring drug dosage of phenytoin.
\end{abstract}

(C) 2017 Published by Elsevier, a division of RELX India, Pvt. Ltd on behalf of Indian Epilepsy Society.

\section{Introduction}

Phenytoin, an anti-epileptic, was first introduced by Merritt \& Putnam in 1938 for the treatment of all forms of epilepsy, except the Petit mal. In 1939, just a year after its introduction as the treatment of epilepsy, $\mathrm{Kimbal}^{20}$ reported that $57 \%$ of patients treated with phenytoin developed some degrees of gingival

\footnotetext{
* Corresponding author at: Department of Periodontics, Bangalore Institute of Dental Sciences and Postgraduate Research Centre, 5/3, Hosur Road, Bangalore 560089, India.

E-mail addresses: docranga@yahoo.com (S. Sridharan), drpriyaperio@yahoo.com (P. S).
}

overgrowth. ${ }^{25}$ Phenytoin is highly bound to plasma protein (90\%), producing a very small free fraction. Despite the high percentage of protein binding, there can be substantial inter individual variation in free phenytoin concentrations, ranging from $9 \%$ to $25 \%$. Therapeutic drug monitoring (TDM) is quick gaining importance as it can be effectively used to monitor drug dosages especially in neurological patients and minimize side effects of the drug. Serum has been widely used for $\mathrm{TDM}^{9}$; Salivary therapeutic drug monitoring offers a number of advantages over serum therapeutic drug monitoring, including lack of pain, lower cost, and wide potential acceptability by patients and physicians. It has the potential to open new approaches to treatment with strategic at-home monitoring at the time a seizure or adverse event occurs 
and to allow the collection of cohort-based, pharmacokinetic, and pharmcodynamic data for populations of persons of varying ages and with different medical conditions who require anticonvulsant medications. $^{29}$

Phenytoin is slowly absorbed from the gut and takes 15 days to achieve the blood plateau; it is metabolized in the liver by microsomal enzymes and excreted from urine in a conjugated form. ${ }^{23}$ Animal studies have shown phenytoin to be concentrated in major and minor salivary gland after systemic administration of phenytoin and to be secreted in the saliva. Controversies exist in literature relating weather salivary concentrations and serum concentrations could affect gingival overgrowth; older studies have taken in account both males and females and also many of these studies have phenytoin along with other medication. ${ }^{13,1}$ Importantly all of these studies had a cross sectional study design, wide age group, not adequate plaque control instruction given prior to the start of the study. Hence till date the exact pathogenesis of phenytoin influenced gingival overgrowth (PIGO) remains a debatable issue. With this background we decided to carry out a longitudinal study on male patients who are on oral phenytoin as a mono drug therapy and followed them for a year with the aim to correlate serum and salivary phenytoin levels to PIGO.

\section{Materials and method}

\subsection{Source of data}

Screening for newly diagnosed epileptic patients from August 2013 to June 2014 in the age group between 13 and 30 years, was done at Victoria Hospital and the medical outpatient department at the Bangalore Institute of Dental Sciences and Post graduate research center,Bangalore, Karnataka; India. Approval from the ethics committee of the Bangalore Institute of Dental Sciences and Post graduate research center was obtained. Inclusion criteria for the patients in the study were male patients between the age 13 to 30 years with a minimum of 20 teeth present excluding the third molars, and who are to start with oral phenytoin drug. Exclusion criteria were female patients, Patients on other drugs which are known to cause gingival overgrowth, Patients who have received any dental treatment in past six months and Patient receiving any long term medication that could interfere with Phenytoin metabolism. Apart from these smokers and alcoholics were also excluded from the study. Demographic data: was obtained using a structured questionnaire; patient's age, gender, socio-economical status, level of education, oral hygiene practices and habits were recorded. Thirty patients who met the inclusion and exclusion criteria and are on the same dose $(100 \mathrm{mg}$ tid) of oral phenytoin
Table 1

Interpretation of biochemical parameters using unpaired $t$-test between two groups.

\begin{tabular}{lll}
\hline & Responder & Non responder \\
\hline Age (year) & $24.07 \pm 4.8$ & $24.27 \pm 5.5$ \\
Gender (male/female) & $15 / 0$ & $15 / 0$ \\
Serum Phenytoin levels $(\mu \mathrm{g} / \mathrm{ml})$ & $14.59 \pm 2.67$ & $14.22 \pm 1.77$ \\
Salivary Phenytoin levels $(\mu \mathrm{g} / \mathrm{ml})$ & $1.42 \pm 0.34$ & $1.38 \pm 0.37$ \\
Mean PI scores & $2.36 \pm 0.31$ & $1.93 \pm 0.71$ \\
Mean GI scores & $1.18 \pm 0.54$ & $1.79 \pm 0.41$ \\
Mean OHI scores & $4.11 \pm 0.36$ & $2.87 \pm 0.54$ \\
\hline
\end{tabular}

were explained in detail about the study and the follow up protocol; and informed consent was obtained for the same. At the end of the one year subjects were classified as responder and non responder based on the gingival status.

\subsection{Clinical measurements}

Thirty patients fulfilling the inclusion and exclusion criteria were recruited in to the study periodontal examination included full mouth recordings of plaque index by Turesky-GilmoreGlickman modification of Quigley Hein Plaque Index (1970), ${ }^{35}$ Gingival index (Loe and Sillness 1963) 22 $^{22}$ and Oral hygiene index (Greene and Vermilion 1960). ${ }^{12}$ All the periodontal examination was carried out by the same examiner $\left(\mathrm{P}^{\dagger}\right)$. Degree of gingival enlargement was scored according to Bokenkamp\&Bohnhorst $1994^{2}$. Basic periodontal therapy was performed before the patients started with the phenytoin drug and they were followed up in regular intervals of 3, 6, 9 and 12 months. Based on the gingival status the end of the one year the patients were divided into 2 groups.

Group 1: Responders - patients who showed clinical signs of gingival overgrowth.

Group 2: Non responders - patients who did not show any signs of gingival overgrowth.

\subsection{Sample collection}

\subsubsection{Saliva collection}

Unstimulated whole saliva samples were collected by drooling method. Patients were instructed to allow saliva to pool in the mouth. With head tilted forward, participants were asked to drool down to collect saliva in the cryovial. Procedure was repeated as necessary until sufficient sample was collected. $1 \mathrm{ml}$ (excluding foam) was adequate for analysis. The whole saliva supernatant was frozen in liquid nitrogen, in aliquots, and subsequently stored at $-20^{\circ} \mathrm{C}$ until analysis.

Table 2

Pearson correlation coefficient between clinical and biochemical parameters.

\begin{tabular}{|c|c|c|c|c|c|c|c|c|}
\hline \multirow[t]{2}{*}{ Groups } & \multicolumn{4}{|c|}{ Serum Phenytoin } & \multicolumn{4}{|l|}{ Salivary Phenytoin } \\
\hline & Parameters & GI & PI & $\mathrm{OHI}$ & Parameters & GI & PI & $\mathrm{OHI}$ \\
\hline \multirow[t]{4}{*}{ Responders } & $\begin{array}{l}\text { Phenytoin } \\
\text { Serum }\end{array}$ & -0.229 & -0.372 & 0.298 & Phenytoin Saliva & 0.012 & 0.127 & 0.434 \\
\hline & GI & 1 & -0.098 & 0.274 & GI & 1 & -0.098 & 0.274 \\
\hline & PI & -0.098 & 1 & -0.21 & PI & -0.098 & 1 & -0.21 \\
\hline & $\mathrm{OHI}$ & 0.274 & -0.21 & 1 & $\mathrm{OHI}$ & 0.274 & -0.21 & 1 \\
\hline \multirow[t]{4}{*}{ Non-Responders } & $\begin{array}{l}\text { Phenytoin } \\
\text { Serum }\end{array}$ & -0.216 & -0.243 & -0.093 & $\begin{array}{l}\text { Phenytoin } \\
\text { Saliva }\end{array}$ & $0.545^{\mathrm{a}}$ & 0.197 & -0.179 \\
\hline & GI & 1 & $0.805^{\mathrm{b}}$ & 0.245 & GI & 1 & $0.805^{\mathrm{b}}$ & 0.245 \\
\hline & PI & $0.805^{\mathrm{b}}$ & 1 & 0.394 & PI & $0.805^{\mathrm{b}}$ & 1 & 0.394 \\
\hline & $\mathrm{OHI}$ & 0.245 & 0.394 & 1 & $\mathrm{OHI}$ & 0.245 & 0.394 & 1 \\
\hline
\end{tabular}

\footnotetext{
a Correlation is significant at the 0.05 level.
}

b Correlation is significant at the 0.01 level. 
Table 3

Previous studies on drug metabolites and gingival overgrowth.

\begin{tabular}{|c|c|c|}
\hline$s / n$ & Year & Study design \\
\hline 1. & $\begin{array}{l}\text { Lascelles et al., } \\
1970^{24}\end{array}$ & cross sectional study, \\
\hline \multirow[t]{2}{*}{2.} & $\begin{array}{l}\text { Bochner et al., } \\
1972^{4}\end{array}$ & $\begin{array}{l}\text { plasma phenytoin levels } \\
\text { cross sectional study, }\end{array}$ \\
\hline & & dosage increments on blood phenytoin levels \\
\hline \multirow[t]{2}{*}{3.} & $\begin{array}{l}\text { Gannaway and } \\
\text { Mawer, } 1981^{10}\end{array}$ & cross sectional study, \\
\hline & & $\begin{array}{l}\text { Exploring the serum concentrations between the usually } \\
\text { recommended range and the individual threshold level at which } \\
\text { toxicity became just detectable }\end{array}$ \\
\hline \multirow[t]{2}{*}{4.} & Kilpatrick and & cross sectional study, \\
\hline & & $\begin{array}{l}\text { To evaluate in treated epileptics the variability in phenytoin } \\
\text { protein binding and to assess the additional clinical value of } \\
\text { measuring the unbound concentration of the drug. }\end{array}$ \\
\hline \multirow[t]{2}{*}{5.} & $\begin{array}{l}\text { Schmidt and } \\
\text { Haenel, } 1984^{33}\end{array}$ & Observational study \\
\hline & & $\begin{array}{l}\text { Studied the range and clinical features that influence the } \\
\text { individual variation of the therapeutic plasma concentration of } \\
\text { phenytoin, phenobarbital, and carbamazepine in epileptic patients } \\
\text { on single-drug therapy. }\end{array}$ \\
\hline 6. & $\begin{array}{l}\text { Thomas and } \\
\text { Joseph } \\
\text { O'Donnell, } 1983\end{array}$ & clinical study \\
\hline
\end{tabular}

\section{No of Inference}

subjects

111 A wide scatter of values was found, with over half outside the therapeutic limits of 10 to $20 \mu \mathrm{g} / \mathrm{ml}$.

12 Therapeutic' range of $10-20 \mu \mathrm{g} / \mathrm{ml}$., is of importance to those who use blood phenytoin levels as a guide to the adequacy of anticonvulsant therapy

The same daily dose of phenytoin tended to give higher serum drug concentrations after intoxication than before.

An inverse relationship was found between the plasma albumin concentration and the phenytoin unbound fraction

Fifty-one percent of the 53 patients receiving phenytoin were completely controlled at either below or above the 10 to 20 micrograms/ml range, suggesting that individual dosage adjustment is preferably based on clinical judgment rather than numerical limits of published therapeutic ranges.

To evaluate the putative relationships between overgrowth severity and gingival inflammation, daily phenytoin dose, age, sex and concentration of phenytoin and its major metabolite in plasma and whole saliva.

7. Peterson et al., Retrospective study, $1991^{30}$

relationships between total and free serum concentrations of phenytoin

8. Thomason Observational study et al., $1992^{36}$

the incidence of phenytoin-induced gingival overgrowth in a population of epileptic patients

9. Ball De et al., Observational study

study and examined the relationships between plasma and saliva concentrations of phenytoin and 5-(4-hydroxyphenyl)-5phenylhydantoin (hpph), the major metabolite of phenytoin

10. Sasaki and Observational study

elucidated the involvement of bFGF (basic fibroblast growth factor) in the pathogenesis of phenytoin-induced gingival overgrowth, measured the concentration of bFGF in the serum

11. Birnbaum et al., Observational study $2003^{5}$

evaluated the intraresident variability among multiple measurements of total phenytoin serum concentrations in nursing home residents.

12 Guncu et al. Observational study

To investigate the relationship between plasma and gingival crevicular fluid (gcf) phenytoin concentrations and the degree of gingival overgrowth in patients with similar gingival and plaque indices and also to determine the risk factors for gingival enlargement.
Epileptic patients have altered serum protein binding of phenytoin and display better correlations between clinical response and free, rather than total, serum levels of the drug.

No significant relationship was found between salivary phenytoin levels and the severity of the gingival overgrowth.

no evidence of a relationship between phenytoin or hpph concentrations in plasma or saliva

Positive correlations were detected between overgrowth severity and gingival inflammation, probing depths, calculus accumulation, plaque score and the measurement gingival margin to mucogingival junction. No correlation was observed between lesion severity and patient age, daily drug dosage, plasma or saliva phenytoin level, or salivary concentration of the major phenytoin metabolite.

Enhanced serum bFGF level was implicated in the pathogenesis of phenytoin-induced gingival overgrowth.

There was a considerable variability in the total phenytoin concentrations in the elderly nursing home resident and measurement of a single total phenytoin concentration should not be used to guide treatment.

The concentration of plasma phenytoin was significantly higher in responders than non responders. 


\subsubsection{Blood collection}

Blood samples $(5 \mathrm{ml})$ from the anticubeital vein was obtained and transferred into pre-heparanized coated vacutainers and immediately sent for analysis.

\subsubsection{Drug analysis}

Serum and Saliva levels of Phenytoin were analyzed using ultraviolet (UV) spectrophotometer. (Randox Daytona plus.) Randox laboratories, Kearneysville, $W V$ at $\lambda$ max value of $275 \mathrm{~nm}$.

\subsection{Statistical analysis}

All the recorded clinical and biochemical parameters were statistically analyzed using SPSS software version 22 IBM.Corp.inc. Descriptive analyses including mean, standard deviation were found for each parameter in 2 groups. Comparison between two groups was performed using unpaired $t$-test. Pearson correlation test was performed for the correlation within each group.

\subsection{Interpretation of biochemical parameters using unpaired t-test between two groups}

The mean values of phenytoin drug metabolite levels in serum of group 1 and group 2 subjects were $14.5 \pm 2.6 \mu \mathrm{g} / \mathrm{ml}$ and $14.2 \pm 1.7 \mu \mathrm{g} / \mathrm{ml}$ respectively, with $\mathrm{p}$ value of 0.66 . The corresponding mean values of phenytoin drug metabolite levels saliva were $1.42 \pm 0.34 \mu \mathrm{g} / \mathrm{ml}$ and $1.38 \pm 0.37 \mu \mathrm{g} / \mathrm{ml}$ with $\mathrm{p}$ value of 0.75 . This difference between the two values was not statistically significant. The mean values of GI, PI and $\mathrm{OHI}$ in group 1 and group 2 were $1.18 \pm 0.54$ and $1.79 \pm 0.41(\mathrm{p}<0.001) ; 2.36 \pm 0.31$ and $1.93 \pm 0.71$ with (p 0.04); $4.11 \pm 0.36$ and $2.87 \pm 0.54$ with $(\mathrm{p}<0.001)$ respectively, which showed statistical significance between the groups in terms of PI and showed statistically high significance between the groups for GI and OHI Table 1 .

\subsection{Pearson correlation coefficient between clinical and biochemical parameters}

In group 1 the correlation of phenytoin drug metabolite levels in serum and saliva with GI, PI and OHI were not statistically significant (GI: r value of -0.229 and 0.012 , PI: $r-0.372$ and 0.127 ; OHI: $\mathrm{r} 0.298$ and 0.434 respectively).In group 2 correlation of phenytoin serum and phenytoin saliva levels with GI, PI and OHI were statistically not significant (GI: $r-0.216$ and 0.545 ; PI: $r$ -0.243 and 0.197 ; OHI: r 0.093 and -0.179 respectively) Table 2.

\section{Discussion}

Correlation between the serum and salivary phenytoin drug metabolite levels did not show a positive correlation with PIGO after the end of one year. The mean serum drug levels were $14.59 \pm 2.67 \mu \mathrm{g} / \mathrm{ml}$ in the responders while the non responders were $14.22 \pm 1.77 \mu \mathrm{g} / \mathrm{ml}$. And the mean salivary levels were roughly one tenth of the serum levels viz $1.42 \pm 0.34 \mu \mathrm{g} / \mathrm{ml}$, and $1.38 \pm 0.37 \mu \mathrm{g} / \mathrm{ml}$ in responders and non responders respectively. Statistically significant correlation existed between plaque index and gingival index which is not of any significance in the context of the study. In our study we included only male patients with mean age of 23-29 years The explanation behind including male patients in present study is that the drug stimulates testosterone metabolism, increasing the level of $5 \alpha$-dihydrotestosterone, a male sex hormone, in the overgrown tissue, which in turn, activates fibroblast growth, suggesting that the reaction may be more intense in male patients. ${ }^{1,32}$ Previous studies have included a wider age group and both the sexes, but phenytoin has shown to have varied rate of absorption across various age groups Evidence suggests that there exists a serum threshold above which overgrowth occurs and that this level was lower in males. ${ }^{19,32}$ Hence there was a need for studies involving PIGO on male subjects which is obscure in literature (Table 3 ).

Incidence of gingival overgrowth can occur early within 3 months of the drug use and it may reach a state of equilibrium often within the first year of the beginning of medication. The incidence and severity is greater in the buccal surface of both upper and lower anterior teeth. ${ }^{25}$ Hence in this study focuses mainly on the drug metabolite levels in the both serum and saliva The drug metabolite values in serum for both the responder and non responder groups ranged between 12 and $19 \mu \mathrm{g} / \mathrm{ml}$ but it was noted that the levels had no correlations with the severity of the gingival enlargement which was measured by an index. ${ }^{2}$ This was in accordance to studies by, ${ }^{11,7,26}$ but is in contrast to other studies which reported that phenytoin concentrations in plasma or saliva are positively correlated with gingival overgrowth. ${ }^{3,6,14,27}$ The salivary drug metabolite levels 0.89 to 2 for both the responder and non responder groups. Interestingly $26 \%$ of the non responder patients had salivary drug metabolite levels greater than $2 \mu \mathrm{g} / \mathrm{ml}$. which opens debates on salivary drug metabolite role in PIGO as suggested by Babkock and Nelson $1964^{3}$. In vitro studies over three decades ${ }^{15,16,6}$ have stressed the importance of a distinct subpopulation of fibroblast which exists in the gingiva and its reaction to the drug metabolite could be genetically determined. ${ }^{17,18}$ It would seem that a certain threshold concentration of the drug or its metabolite is necessary to "activate" gingival fibroblasts, and increasing the levels of the drug above this threshold did not increase the severity of the lesion. ${ }^{8,21}$ This could be one possible explanation to why only certain patients subjected to the same drug have side effects. Salivary and crevicular fluid levels may provide more pertinent information on patient's susceptibility to PIGO. It may be pertinent to note however, that dental plaque will adsorb phenytoin from the saliva. ${ }^{28}$ Plaque may not only mediate its effect on overgrowth via induction but also hold phenytoin in direct contact with the tissues concerned.

The strength of this study would be its longitudinal study design, where in all the patients were followed from day 1 of start of the drug as a mono therapy to one year, reinforcing adequate plaque control methods throughout the study, age and gender bias was taken into account for; the progression of this study would be on relating to the pathogenesis of PIGO on the tissue samples obtained. Within the limitation of this study it could be concluded that neither serum nor salivary drug metabolite levels could be correlated to the degree of PIGO, it could be proposed that genetic predilection plays a crucial role in susceptibility to the side effects of the drug.

\section{References}

1. Ball DE, McLaughlin WS, Seymour RA Ramali F. Plasma and saliva concentrations of phenytoin and 5-(4-hydroxyphenyl)-5- phenylhydantoin in relation to the incidence and severity of phenytoin-induced gingival overgrowth in epileptic patients. I Periodontol. 1996;67:597-602.

2. BokenKamp A, Bohnhorst B, Beier Christian. Nifedipine aggravates cyclosporine A-induced gingival hyperplasia. Pediatr Nephrol: J Int Pediatr Nephrol Assoc. 1994;8:181-185.

3. Babcock JR, Nelson GH. Gingival hyperplasia and dilantin content of saliva: a pilot study. J Am Dent Assoc. 1964;68:195-198.

4. Bochner F, Hooper WD, Tyrer JH, Eadie MJ. Effect of a delayed-action phenytoin preparation on blood phenytoin concentration. J Neurol Neurosurg Psychiatry. 1972:35:682-684.

5. Birnbaum AK, Hardie NA, Conway JM, et al. Phenytoin use in elderly nursing home residents. Am J Geriatr Pharmacother. 2003;1:90-95.

6. Conard GJ, Jeffay H, Boshes L, Steinberg AD. Levels of 5,5-diphenylhydantoin and its major metabolite in human serum, saliva and hyperplastic gingiva. $J$ Dent Res. 1974;53:1323-1329.

7. Dahllof G, Modeer T. The effect of a plaque control program on the development of phenytoin-induced gingival overgrowth. A 2-year longitudinal study. J Clin Periodontol. 1986;13:845-849. 
8. Daley TD, Wysocki GR, Day C. Clinical and pharmacologic correlations in cyclosporine-induced gingival hyperplasia. Oral Surg Oral Med Oral Pathol. 1986;62:417-421.

9. Gidal BE, Garnett WR. Epilepsy, In: DiPiro JT, Talbert RL, Yee GC, eds, et al. Pharmacotherapy. 6th ed. New York: McGraw-Hill; 2005:1023-1048.

10. Gannaway DJ, Mawer GE. Serum phenytoin concentration and clinical response in patients with epilepsy. Br J Clin Pharmacol. 1981;12:833-839.

11. Guncu GN, Caglayan F, Dincel A, Bozkurt A, Sayg S, Karabulut E. Plasma and gingival crevicular fluid phenytoin concentrations as risk factors for gingival overgrowth. J Periodontol. 2006;77:2005-2010.

12. Greene JC, Vermillon JR. Oral hygiene index simplified. J Am Dent Assoc. 1964;68:7-13.

13. Henskens YMC, Strooker H, Van den Keijbus PAM, Veerman EC, Nieuw AV. Salivary protein composition in epileptic patients on different medications. $J$ Oral Pathol Med. 1996;25:360-366.

14. Hassell T, O’Donnell J, Pearlman J, Tesini D, Murphy T, Best H. Phenytoininduced gingival overgrowth in institutionalised epileptics. J Clin Periodontol. 1983; 11:242-253.

15. Hassell T. Evidence for production of an inactive collagenase by fibroblasts from phenytoin-enlarged human gingivae. J Oral Pathol Med. 1982;11:52 Page.

16. Hassell TM, Buchanan J, Cuchens M, Douglas R. Fluorescence activated vital cell sorting of human fibroblast subpopulations that hind cyclosporine. Am J Dent Res. 1988;67:273.

17. Hassell T. Stimulation and inhibition of fibroblast subpopulations by phenytoin and phenytoin metabolites: pathogenic role in gingival enlargement. Am Acad Pediatr Denistry. 1981;3:137-153.

18. Hassell T, Gilbert G. Phenytoin sensitivity of fibroblasts as the basis for susceptibility to gingival enlargement. Am J Pathol. 1983;112:218-223.

19. Ishida H, Kondoh T, Kataoka M, et al. Factors influencing nifedipine-induced gingival overgrowth in rats. J Periodontol. 1995;66:345-350.

20. Kimball OP. The treatment of epilepsy with sodium diphenyl hydantoinate. $J$ Am Medical Assoc. 1939;112:124.

21. Kilpatrick CJ, Wanwimolruk S, Wing MH. Plasma concentrations of unbound phenytoin in the management of epilepsy. Br J Clin Pharmacl. 1984;17:539-546.
22. Löe H, Silness J. Periodontal disease in pregnancy. I. Prevalence and severity. Acta Odontol Scand. 1963;21:533-551.

23. Loeser EW. Studies on the metabolism of diphenylhydantoin (dilantin) Neurology (Minneap). 1961;11:424-429.

24. Lascelles PT, Kocen RS, Reynolds EH. The distribution of plasma phenytoin levels in epileptic patients. J Neurol Neurosurg Psychiatry. 1970;33:501-505.

25. Merritt HH, Putnam TJ. Sodium diphenylhydantoinate in the treatment of convulsive disorders. J Am Med Assoc. 1984;8:1062-1067.

26. Modeer, Dahllof G. Development of phenytoin-induced gingival overgrowth in non- institutionalized epileptic children subjected to different plaque control programs. Acta Odontol Scand. 1987;45:81-85.

27. McGaw TM, Lam S, Coates J. Cyclosporin-induced gingival overgrowth: correlation with dental scores and cyclosporin levels in serum and saliva. Oral Surg Oral Med Oral Pathol. 1987;64:293-297.

28. Majola MP, McFadyen ML, Connolly C, Nair YP, Govender M, Laher MH. Factors influencing phenytoin induced gingival enlargement. J Clin Periodontol. 2000;27:506-512.

29. Paxton JW. Effects of aspirin on salivary and serum phenytoin kinetics in healthy subjects. Clin Pharmacol Ther. 1980;27(2):170-178.

30. Peterson Gregory KM, Boo HC, Von Witt Richard J. Clinical response in epilepsy in relation to total and free serum levels of phenytoin. Ther Drug Monit. $1991 ; 13: 5$.

32. Sooriyamoorthy M, Gower BM. Androgen metabolism in gingival hyperplasia induced by nifedipine and cyclosporin. J Periodontal Res. 1990;25:25-30.

33. Schmidt D, Einicke I, Haenel F. The influence of seizure type on the efficacy of plasma concentrations of phenytoin, phenobarbital, and carbamazepine. Arch Neurol. 1986;43:263-265.

34. Sasaki T, Maita E. Increased $\beta$ FGF level in the serum of patients with phenytoin- induced gingival overgrowth. J Clin Periodontol. 1998;25:42-47.

35. Turesky S, Gilmore ND, Glickman I. Reduced plaque formation by the chloromethyl analogue of victamine C. J Periodontol. 1970;41:41-43.

36. Thomason I, Seymour M, Rawlins RA. Incidence of phenytoin induced gingival overgrowth in epileptic patients in general medical practice. Commun Dent Oral Epidemiol. 1992;20:288-291. 